\title{
Pseudomyxoma peritonei
}

INSERM

\section{Source}

INSERM. (1999). Orphanet: an online rare disease and orphan drug data base.

Pseudomyxoma peritonei. ORPHA:26790

Pseudomyxoma peritonei is characterized by disseminated intra-peritoneal mucinous tumors and mucinous ascites in the abdomen and pelvis. 